\title{
THE
}

$5-17-2009$

\section{New England Technical Services Librarians (NETSL) Spring Conference: Working the Cataloging Landscape: Fishing, Mining, and Harvesting}

Andrée J. Rathemacher

University of Rhode Island Library, andree@uri.edu

Martha Rice Sanders

HELIN Consortium, martha.sanders@iii.com

Follow this and additional works at: https://digitalcommons.uri.edu/lib_ts_pubs

Part of the Library and Information Science Commons

\section{Citation/Publisher Attribution}

Rathemacher, Andrée J., and Martha R. Sanders. "2009 New England Technical Services Librarians (NETSL) Spring Conference: Working the Cataloging Landscape: Fishing, Mining, and Harvesting." , (2009). doi: 10.1016/j.serrev.2009.05.010.

This Article is brought to you for free and open access by the Technical Services at DigitalCommons@URI. It has been accepted for inclusion in Technical Services Department Faculty Publications by an authorized administrator of DigitalCommons@URI. For more information, please contact digitalcommons-group@uri.edu. 


\section{New England Technical Services Librarians (NETSL) Spring Conference: Working the Cataloging Landscape: Fishing, Mining, and Harvesting}

\section{Andrée J. Rathemacher and Martha Rice Sanders}

The organization known today as NETSL (New England Technical Services Librarians) began in 1923 as the Boston Regional Group of Cataloguers and Classifiers (BRGCC). The organization adopted its current name in 1959 when membership grew to include librarians throughout the region. At the same time, it became a section of the New England Library Association (NELA) while retaining its status as a regional group of the American Library Association. According to its bylaws, NETSL's purpose is "to bring together for the exchange of ideas and discussion of problems all persons in the region interested in technical services in libraries and to cooperate with regional and national agencies having related interests." One on NETSL's core missions is offering leading-edge programs and discussion groups at the NELA annual conference in the fall and a topical annual conference in April held at the College of the Holy Cross in Worcester, Mass. This report discusses the program of the 2009 NETSL annual spring conference held on Friday, April 17, entitled "Working the Cataloging Landscape: Fishing, Mining, and Harvesting." Slides of the presentations are available at http://www.nelib.org/netsl/conference/2009/index.htm (accessed May 17, 2009).

\section{"Metadata is a Plural Noun"}

Karen Coyle opened with "Metadata is a Plural Noun." Coyle is a librarian and consultant who has worked for over twenty years on the California Digital Library of the University of California libraries and writes frequently on technical topics for the Journal of Academic Librarianship and other publications.

Coyle began by broadening the concept of what metadata is. The standard definition of metadata is "data about data," which, according to Coyle, is catchy but wrong. Coyle asserted that metadata are data about things, like books or artifacts in a museum. Furthermore, metadata are constructed by people for a purpose. Most importantly, metadata need to be actionable; we need to be able to do something with the data. Coyle gave an example of a subway map. A subway map is metadata; it is an artificial representation of reality, created by people in order to serve the purpose of navigation. 
Today, metadata are sent through computers, which requires that metadata be actionable, "interact(ionable)," available where needed, and available for use. Unlike the folded paper map of the past, for example, Google maps allow the user to get directions, enlarge and print the map, and find restaurants among other sites. A Google map can be sent to a portable device and can be mashed up with other data, such as a list of hotels in a city. Metadata are for use. The more metadata are used, the more uses they have, and the more value they create.

Coyle next focused on library metadata. Librarians have been creating metadata forever, from the tags hanging from scrolls in Roman libraries to the card catalog, which was a revolutionary technological invention because it was expandable, data could be added at any point, and allowed for multiple entries for a single item. Now, our catalogs have taken the form of MARC records in a database. The problem is that our textual metadata are wrapped up in a record, and controlled by a database. Users can only search for and interact with our metadata in specific ways. Our databases are searchable on the Web, but our data are not.

Coyle challenged her listeners to "think outside the (catalog) box," to think about our data as data, not as catalog entries, and to think about our data interacting with other data on the Web. To illustrate the potential of cataloging metadata unbound, Coyle showed the WorldCat Identities page for Emily Dickinson, http://www.worldcat.org/identities/lccn-n79-54166 (accessed May 17, 2009). She explained that OCLC had mined the WorldCat database for everything written by or about Emily Dickinson and presented the data in a way that enhanced what we know about the poet. For example, a "Publication Timeline" shows graphically the relative number of publications about Emily Dickinson and by Emily Dickinson, including those published posthumously. This enables researchers to visually gauge the evolution of interest in and scholarship about the poet.

Breaking our metadata out of the box stands contrasts with the FRBR (Functional Requirements for Bibliographic Records) user tasks traditionally associated with information-seeking behavior: find, identify, select, obtain. Coyle finds these tasks linear and limited, and feels that if this is all libraries plan to accomplish, we won't survive. These tasks are only a tiny part of information seeking. In contrast, the library should be involved before information seekers approach the catalog and long after they go to the shelf. Libraries and their metadata should play a part not only in structured finding, but in everything beyond that, such as annotating, organizing, writing, and sharing, all of which make use of bibliographic data.

Coyle then connected these ideas to the emerging project of the semantic Web. Coyle 
explained that the Web allows us to make links between documents. However, the problem is that until we click we really don't know to what we're connecting. A link is simply a link. The semantic Web, on the other hand, identifies entities in documents on the Web. So, for example, a page on Moby Dick by Herman Melville could tag Moby Dick as the title of a book, Melville as an author, New Bedford as a geographic location, and whales as a topic. Connections could then be made between authors and their titles, and between these entities and related entities and documents.

One aspect of the semantic Web is Linked Open Data, which involves "using the Web to connect related data that wasn't previously linked or using the Web to lower the barriers to linking data currently linked using other methods" Links are made between information based on its own content, on what is already linked and what tends to be connected, which can then create new information. Coyle gave an example of how data from the MARC record could work as Linked Open Data. Each piece of a name on an authority record such as "Darwin, Charles, 1809-1882" could be tagged as "family name," "fore name," "birth year," and "death year." By freeing these data elements and connecting them with similar information, researchers could ask and receive answers to such questions as "What important world events happened during Darwin's lifetime?" "Who was writing on science at the same time?" and "Show me a map of important places in Darwin's life."

The Open Library project, http://openlibrary.org/ (accessed May 17, 2009) is doing something similar to what linked open data could accomplish by using its data in partnership with Creative Commons to determine the copyright status of a work. The earliest publication date for a work is identified and fed to a copyright analysis program which then determines copyright status. Another example is Wikipedia. The works listed in the entry for an author is entered by hand. If library data were available for mining, a more complete list of an author's works could be generated automatically, including all editions and translations, with links library holdings. The simple fact is, bibliographic data are used everywhere, so opening up library bibliographic data would be a huge service, especially since libraries have the most complete and accurate bibliographic data due to the rules we follow in its creation.

Coyle posed the question "What can libraries do to make our data useful?" The answer, she explained, is to make our data harvestable so others can use it and to identify our data structures and vocabularies for use on the web. We need to define the data elements in our records, such as subjects, names, resource types, languages, places, and roles, and how they connect. The world is discovering the need for controlled vocabularies, and we have many of them. Libraries are the only organizations with name authorities for every published author, and we should make our name authorities 
available on the Web. The Library of Congress has plans to do exactly this for MARC data elements with their ID.LOC.GOV Web Service, http://id.loc.gov/ (accessed May 17, 2009). A similar project is the National Science Digital Library Metadata Registry at http://metadataregistry.org/ (accessed May 17, 2009) which supports metadata interoperability by defining and sharing RDA vocabularies; for example, the concept of a "work" or groups of musical instruments.

Coyle believes that libraries must also make our data more "data-like" and our systems more "cloud-like." We can make our data more "data-like" by encoding data elements, such as birth dates and death dates. We should structure our data, keeping in mind not only how it displays in the catalog, but how it can be used outside the library. To make our systems more "cloud-like," the closed catalog has to go. The catalog 2.0 will pull data in, such as author biographies, tables of contents, and book reviews. It will also allow catalog data to be used by other applications. As libraries, we have rare materials that are not available on amazon.com. If our library data does not enter the cloud, it will be like a "digital burning of the Library of Alexandria" because people engaging in research in the cloud will only be working with a small fraction of the universe of information. According to Coyle, "The long tail of books is incredibly long, and we're the ones who have it."

\section{"RDA: Boondoggle or Boon? And What About MARC?"}

At one breakout session, Rick Block (head, Special Collections Metadata and Cataloging, Columbia University and 2008 winner of the Library Journal Teaching Award) discussed Resource Description and Access (RDA), the new cataloging code being written to replace AACR2. He began by imagining why NETSL had asked him to present this talk and gave reasons, including his having been quoted in Library Journal that RDA was a disaster and that he is both a working librarian and library educator, teaching cataloging at two different library schools, the Palmer School of Information and Library Science at Long Island University and the Pratt Institute School of Information and Library Science.

Block then discussed what RDA is - a content standard using a FRBR-based approach to structuring bibliographic data in more explicitly machine-friendly linkages using more emphasis on relationships and roles and less reliance on cataloger-created notes and text strings. It is intended to be a flexible and adaptable online project for a set of guidelines focused on user tasks (find, identify, select, obtain) to be used with various 
encoding schemata such as MODS, MARC and Dublin Core. In addition, it will attempt to improve how catalogers present relationships among resources. Built on FRBR, FRAD (Functional Requirements for Authority Data), AACR2, and ISBD (International Standard Bibliographic Description), it is not intended to be a display standard or metadata schema, a rigid set of rules, or have instructions on creating subject headings (yet) or classification numbers. The goals include that RDA be written in plain English and usable in other language communities, be independent of the storage format, medium or system, and be readily adaptable to newly emerging data structures.

After reviewing the stakeholders in the successful adoption of RDA and its structure, Block discussed various reactions to the RDA drafts, stating that these generally fall into two camps, one arguing that it is too extreme and that other that it is not extreme enough. The Joint Steering Committee, which is the body drafting RDA, states that it must shift the theoretical framework of cataloging while ensuring that already existing bibliographic works remain valid, making the task of finding the right balance quite difficult. Those arguing that RDA is too extreme claim that abandoning ISBD would be a step backward, that FRBR is an untested theory, that the language in RDA is incomprehensible, and that the costs of implementation will outweigh any benefits. They also state that communities other than libraries won't adopt RDA so catering to multiple audiences will pollute cataloging standards. Those arguing that the changes in RDA are not extreme enough state that too much is relegated to the description of texts, that backward-compatibility prohibits needed changes, that the FRBR integration is insufficient, and that it is mired in past thinking. In addition, it is argued that no standard can effectively be applied to both analog and digital records, so new codes must choose to concentrate on digital description or risk being born rejected by the forward thinking. Block then reviewed the report from the Working Group on the Future of Bibliographic Control, found at http://www.loc.gov/bibliographic-future/ (accessed May 17, 2009), emphasizing its call to suspend work on RDA.

He covered the RDA draft review process, saying that some positive features of RDA include its organization of instructions around a clearly defined element set, the effort to support both current and forward-looking implementations, the application of FRBR and FRAD data models, the definition of a place for subject entities and relationships in the RDA structure, and the effort to support the application of RDA outside of an English-language environment. Criticisms of RDA include the flawed, difficult process for constituency review of the RDA draft, its frustrating combination of a forwardlooking structure with the retention of much of the case law approach of the past and that it failed to meet many of its objectives, particularly with its lack of clarity.

Regarding whether or not RDA would be implemented, Block discussed Heidi 
Hoerman's presentation at OLAC/MOUG/NOTSL (Online Audiovisual Catalogers/Music OCLC Users Group/Northern Ohio Technical Services Librarians) in 2008, which predicted that RDA would die a quiet death but that its aims would be realized in time. Even if it is as bad as the detractors say, it may have important things to communicate about cataloging, that RDA may be a stepping stone to the next standard which may be the important step needed, or alternatively, that RDA may prove to be the wonderful change it is meant to be.

Block spent some time reviewing the arguments for and against the continuation of MARC as a transmission standard for cataloging. The RDA/MARC Working Group continues to work on proposed changes to MARC21 to allow the encoding of RDA data as the RDA online product will include mappings to MARC. However, MARC is just one possible encoding schema for RDA data, and the Joint Steering Committee has backed away gradually from their original statement that RDA could be expressed in MARC21 easily. At the same time, it is rumored that LC is considering the discontinuation of MARC21 updates sometime next year. Block went on to point out the richness of MARC with nearly 2000 elements available, even though current cataloging may not exploit much of that richness. He believes the rumors of MARC's death are exaggerated, but warned the audience that the "cult of MARC" may keep us from moving forward and that the pursuit of the perfect record must end.

After reviewing the planned features of the RDA online product, his talk concluded with a discussion of the testing planned for RDA, to occur the six months following its publication, which time is currently set to be sometime in the third quarter of 2009. Coordinated by LC, the National Agricultural Library, and the National Library of Medicine, other Program for Cooperative Cataloging members will participate, including at least one participant from Columbia University, comparing the use of RDA with AARC2. While the testers are creating bibliographic data and populating a MARC record with it, they will determine possible changes to MARC to accommodate this new data and assess the financial impact of training and workflow, as well as how well RDA records co-exist with AACR2 records. The testing will also give some insight into how well FRBR may be applied and how applicable it is to all types of materials. The success of this test may be hampered by whether or not the entire RDA will be openly accessible. One unknown factor is what OCLC plans to do, a question raised at every presentation about RDA that this listener has heard.

"Fishing Upstream: Publisher-Supplied Cataloging and Libraries" 
A second breakout session on publisher-supplied cataloging began with Andreas Biedenbach (eProduct manager, New York office, Springer Science and Business Media) who outlined Springer's mechanisms for supplying MARC records for their publications to libraries.

Biedenbach set the context by explaining that bibliographic data, full-text content, and lists of references are generated for all Springer electronic journals and books. These data are created not only for libraries, but for other entities such as search engines, link resolvers, document delivery services, subscription agencies and booksellers, digital preservation platforms such as Portico and for the SpringerLink content delivery platform. The generation and distribution of metadata is important to the publisher, as well as to librarians, because it helps end users find the publication and increases usage. MARC records for library catalogs are one part of this data stream.

Biedenbach confirmed the importance of including MARC records for e-resources in library catalogs by noting that after two Australian libraries loaded catalog records for Springer e-books, full text downloads of book chapters increased dramatically. He then outlined Springer's two-pronged strategy for producing MARC records for libraries. For libraries that do not have access to OCLC, Springer provides MARC records that can be downloaded for free from their site at http://www.springer.com/marc (accessed May 17, 2009). They are generated using Springer metadata, in which XML ONIX data are converted to MARC format. MARC records are available for all Springer eBooks, eBook Subject Collections, and Protocols and are updated monthly. Biedenbach pointed out that these MARC records do not use LC subject headings, as they are not created by catalogers and are distributed globally, not just for the American market.

Springer also partners with OCLC to create customized MARC records for OCLC subscribers. Records are available in groups as OCLC WorldCat Collection Sets or can be downloaded using the OCLC Connexion client. OCLC guarantees that full MARC records will be available four weeks after data delivery by Springer. In addition, Springer works with companies, such as Serials Solutions and ExLibris SFX, which also provide MARC records, to deliver current title and holdings data for e-journal and ebook packages.

Biedenbach concluded by outlining the challenges of publisher-supplied metadata. One challenge is that Springer needs to supply its metadata to customers in different formats, such as Excel, ONIX, or MARC21. Biedenbach hopes that the KBART (Knowledge Bases and Related Tools) initiative will help create standards for data 
delivery between publishers and knowledge-base providers. Another challenge is the geographical variability of cataloging standards for character sets, serial title changes, and subject classifications, which, for example, requires Springer to map their own subjects to a number of different controlled vocabularies. Springer is working with its partners to reduce the time lag between Springer's delivery of data and final processing and to better explain Springer's business model so that third parties understand the collections and packages through which their electronic products are sold.

Following on Biedenbach was Leslie Horner Button (associate director for collection service and interim associate director for Research and Learning Services, University of Massachusetts, Amherst (UMass Amherst)). Button argued that libraries are at a turning point regarding bibliographic access to information resources. Libraries' goal in providing bibliographic access is to make resources available to users as quickly as possible. We have accomplished this by creating records in our local catalogs to serve local users and then adding these records to national bibliographic utilities. However, licensed electronic resources have turned upside down the need to add records to bibliographic utilities, as vendor-provided records are readily available to both libraries and bibliographic utilities.

Button explained that vendor records make it easy for libraries to make resources available to their users quickly, even if the quality of the records is not ideal. Vendor records are even more useful in the context of increased pressure on technical services staffing budgets. Button relayed how six to seven years ago, UMass Amherst lost one third of its library's cataloging staff due to retirement packages. While staffing declined, the amount of material purchased remained fairly constant. At the same time, purchasing of e-resources skyrocketed, especially the purchase of bundled aggregations of e-resources.

Before the staffing shortages, the libraries at UMass Amherst became familiar with vendor-supplied records. They purchased WorldCat records for microfilm sets, which greatly enhanced the use of the microform collections and acquired catalog records for Netlibrary e-book titles from NELINET. In 2002, they started using PromptCat for approval books. This was traumatic at first, as the records contained mistakes, but they realized that without loading the PromptCat records they simply couldn't cope with the amount of material they received. More recently, they re-engineered book selection workflow by working with YBP Library Services to get brief vendor records for books on order into the catalog, eliminating ordering backlogs and duplicate labor.

With this background, Button said that the UMass Amherst libraries felt comfortable, from year 2000 on, using vendor-supplied records for e-resources, when available, 
including SFX MARCit! records for serials. Button feels that the records supplied by YBP, PromptCat, and SFX MARCit! all work well and, being MARC-based, integrate into the local catalog.

Given the experiences at UMass Amherst, Button thinks it makes sense to "fish upstream" and use vendor-supplied catalog records. Because book production is now electronic, metadata are captured during the production process. At the same time, libraries are buying large bundles of e-journal and e-book content that they do not have the capacity to catalog in-house. Hundreds or thousands of vendor-supplied records can be batch-loaded quickly and provide the basic elements needed for discovery.

Despite the advantages of vendor-supplied cataloging, Button acknowledged that there are challenges to reusing vendor-created metadata. ONIX metadata are created for business purposes, not for library purposes. For example, Springer records had no subject authority control, while records for Gale's Eighteenth Century Collections Online initially had no subject headings. Nonetheless, patrons managed to find and use the material.

Keeping up with vendor-supplied catalog records can also be a challenge. When content in a leased package changes, libraries need to receive a notification so they can update corresponding catalog records. Records should be available in a single, downloadable file, as multiple files create a lot of work. Button hopes that vendors will work more closely with OCLC to include their records in WorldCat Collection Sets so that the records can be improved centrally, instead of being corrected by each library locally.

Button noted that vendors and libraries have similar interests in creating metadata: they both want to make resources easily discoverable and accessible to a common audience, both need to contain costs and take advantage of efficiencies. What stands in the way of more effective collaboration is the fact that standards are new and evolving, and the technical environment has changed since MARC was invented.

Button stated that in the future, we need to take our metadata out of the catalog to the network level and the semantic Web. The catalog is no longer the only or the preferred discovery tool for information. A lack of subject headings in vendor records might be overcome by newer subject approaches, such as FAST (Faceted Application of Subject Terminology), SKOS (Simple Knowledge Information System), the Virtual International Authority File (VIAF), or even social tagging.

During the question-and-answer session that followed, attendees commented that when 
using vendor-supplied cataloging, libraries need to spot check the records to minimize problems and identify any batch processing needed. At the same time, many local practices need to be eliminated to take full advantage of efficiencies offered by vendor records. Others noted that our anxieties are generational. Today's students can deal with inconsistencies in metadata as long as they can find the resources they need.

\section{Spotlight on Organizations and Presentation of NETSL Award for Excellence in Technical Services}

After lunch at each NETSL conference, a speaker briefly highlights another organization in New England with complementary goals to NETSL's. This year Brooke Lippy (assistant head, Allen Library, University of Hartford) described the work of the New England Chapter of the Music Library Association and how it complements the work of NETSL. Then Amy Benson, president of NETSL, presented the 2009 NETSL Award for Excellence in Technical Services to Martha Rice Sanders, knowledge management librarian for the HELIN Consortium.

\section{"What Users \& Librarians Want from Metadata: The OCLC Year"}

Ted Fons gave the afternoon presentation "What Users \& Librarians Want from Metadata." Fons recently became the director of WorldCat Global Metadata Network after many years as a senior product manager and then director of customer services at Innovative Interfaces. He described the "four seasons of metadata at OCLC."

According to Fons, "summer" at OCLC brought new ways of think about metadata management in which large information hubs promote discovery and delivery. OCLC has partnered with many other data managers, such as Google, ERIC, and Ask.com, to become interoperable. Current research shows that in the first part of 2008, nearly 50 percent of hits on WorldCat came from search engines. In addition, the most growth of the past ten years in the database came from non-English contributions. In 1998, 36 percent of WorldCat was not in English, while in 2008 it was just over 50 percent. Building on Karen Coyle's call to open up our "silos" of data, Ted discussed how OCLC has established partnerships with publishers to exchange data and, in the process, enhance the data pushed back out to the publishers. In addition, The Deutsche Nationalbibliothek, the Library of Congress, the Bibliothèque nationale de France, and OCLC cooperate in creating the Virtual International Authority File to link national authority records and move closer to universal bibliographic control. 
In the "fall," OCLC contrasted what users and librarians want from metadata using results from usage studies of WorldCat conducted separately with each of those communities. Key findings of these studies show that end users bring to WorldCat their expectations from popular Web sites and that different groups of end users have differing priorities, though there are some commonalities. End users expect movement from discovery to delivery to be seamless. To that end, enhanced information (summaries, tables of contents, subject information, etc.) is most important to the description of analog materials while the link to the content is most important to econtent. For end users, keyword searching dominates, using one to three terms on average, with a very high failure rate of 20 to 40 percent. OCLC surveyed librarians in 2008 and received nearly 1400 responses. Librarians believe merging duplicate records to be the most important enhancement to WorldCat, followed by adding tables of contents and summaries, and correcting typos to bibliographic records. They also asked for more authority to correct OCLC records, which measure has been adopted with the current OCLC Expert Community Experiment, running February through July. At the time of the NETSL conference, nearly 1000 OCLC member libraries had touched over 14,000 bibliographic records in WorldCat.

"Winter" brought more cooperative metadata management as OCLC moved from focusing on creation and control of data to exchanging and linking it. While the prevailing belief in the blogosphere is that data should be free and open, the reality is that nearly all data providers, including Amazon, Wikipedia, and Twitter, have terms and conditions imposing some degree of restriction on the reuse and transfer of their data. Balance must be achieved between where the money comes from (public, social, or private sectors) and where it goes. In the current landscape, which is rich in contradictions, OCLC's policy for data sharing and reuse agrees with the norm. Fons asked if data should be stored like in a warehouse or allowed to flow freely like a river. OCLC wishes to help libraries lower their costs while allowing them to expose their data everywhere possible on the Web.

Fons began his discussion of "springtime" at OCLC by reviewing the FRBR entity levels (work, expression, manifestation, item) and the OCLC FRBR work-set algorithm, which clusters together works by creating work keys using author and title information. OCLC is experimenting with using these work keys in a new project, called, "work pages beta." Work pages contain sections on details, editions, related works, audience level, publication history, classification, and countries of publication. This project links the bibliographic information found in WorldCat with other data available on the Web to dynamically bring in enhanced content such as maps of the countries where a work 
has been published and the cover art of related works. Fons predicted that such sharing and interweaving of Web-based content would increase and bring users more of what they need and want.

\section{"Mining the OPAC: Next Generation Catalog Panel"}

The conference concluded with a panel of three librarians who discussed catalog innovations at their respective institutions. Daniel Lovins (metadata and emerging technologies librarian, Sterling Library, Yale University) spoke about Yale's next generation OPAC, which is based on the open-source VuFind software created by Villanova University. After deciding that the traditional vendor-supplied OPAC was technologically obsolescent, the Sterling Library received a Mellon grant to implement their version of VuFind, "YuFind." YuFind has many OPAC 2.0 features such as faceted navigation, relevancy rankings, circulation status, integration with Google book search, RSS feeds, links to Wikipedia, cover images from Syndetic Solutions, and social tagging. Lovins found that while the open software made experimentation easy, a lot of customization was needed, especially to tweak relevancy rankings. The faceted data exposed inconsistencies in their records that had built up for three hundred years. Catalogers are developing work flows to query the database for all records that meet certain criteria and then update records and codes as needed. The OPAC 2.0 has raised questions about cataloging standards and what is necessary versus optional in a record. Librarians are asking how users interact with records in a faceted, relevancy-ranked environment, and what is the core set of metadata elements that every record has to have.

Kevin Kidd (library applications and systems manager, O-Neill Library, Boston College) discussed Boston College's implementation of Primo, an ExLibris OPAC 2.0 product, and their efforts to decouple online library services from silo-based applications. Primo provides a single, Google-like search across all local collections and supports user tagging, ratings and reviews, relevancy ranking, RSS feeds, and faceted searching. Primo allows researchers to search across the library catalog, online databases, the institutional repository, and a federated search system. Kidd also described Boston College's Aerie Project, a Web services development infrastructure to aggregate and customize unrelated systems. The Aerie Project will enable individual library system components to be embedded in other systems. For example, students can click on a course and access documents on reserve without searching the catalog. Faculty can search and request documents to place on reserve while viewing their teaching schedules. Any user can create an individualized "e-shelf" and have it accessible in multiple campus applications. A "resource recommender" allows 
bibliographers to publish useful sources to people enrolled in a particular course.

The last speaker of the day was Remlee Green, a librarian for Web technologies and neuroscience at the Massachusetts Institute of Technology Engineering and Science Libraries. Green discussed why the MIT Libraries implemented WorldCat Local, several of the challenges encountered during implementation, and the pros and cons of adopting the system. Green explained that MIT had been looking at catalog alternatives for five years in an attempt to find something more intuitive and user-friendly. They decided to implement WorldCat Local because of its OPAC 2.0 features and general usability, low maintenance needs, relatively inexpensive cost, and links to Boston Library Consortium holdings. Green feels that OCLC is still working out some kinks in the system, although they've been responsive to problems and concerns. Since WorldCat Local is based on OCLC holdings, it only contains about 90 percent of MIT's holdings, so it is not the equivalent of the library catalog, which users need to understand. Green also finds it frustrating that the library cannot troubleshoot the system; problems must be reported. Green reported that users like features such as faceted browsing, user profiles, and being able to access WorldCat Local on their mobile phones. They are also pleased with being able to view other libraries' holdings as well as the "FRBR-ization" of records which eliminates duplicate listings of items. Usability tests and a survey revealed that 70 percent of respondents thought WorldCat Local was better than the library catalog. On the negative side, Green reported that the system often slows down or times out, and some local notes fields don't display. An area of confusion is that WorldCat local contains some records for journal articles, which might lead users to think that the MIT Libraries only have those articles that appear in a WorldCat Local search. MIT also wants to load theses and technical reports, and records not in MARC format, such as items from DSpace, MIT's open-source platform for accessing, managing, and preserving scholarly works. Green noted that WorldCat Local has inspired them to clean up WorldCat holdings for deleted items, and to investigate batch reclamation for items they have but are not in WorldCat. 